\title{
Potassium Iodate: A New Versatile Reagent to Determine the Iodine Value of Edible Oils
}

\author{
Sowmya Palahally Thimmappa ${ }^{1, * \mathbb{D}}$, Anitha Sudhir ${ }^{1 \mathbb{D}}$, Kuriya Madavu Lokanatha Rai ${ }^{2 \mathbb{D}}$, Hemavathi \\ Nagaraju Deepakumari ${ }^{3}$ (D), Mahesh Bhatt ${ }^{4}$ (D) \\ Department of Chemistry, Vidyavardhaka College of Engineering, Mysuru-570002, India \\ Department of Studies in Chemistry, University of Mysore, Manasagangothri, Mysuru-57006, India \\ Department of Chemistry, Bharathi College, Mandya-571422, India \\ Department of Chemistry, Poorna Prajna College, Udupi-576101, India \\ Correspondence: ptsowmya8@gmail.com (S.P.T.);
}

Scopus Author ID 57192986128

Received: 31.05.2021; Revised: 4.07.2021; Accepted: 7.07.2021; Published: 5.09.2021

\begin{abstract}
Iodine value is regarded as one of the essential parameters to establish edible oils' quality and identity. The research paper describes a simple visual titrating procedure to ascertain the iodine number of oils. The method involves adding potassium iodate to polyunsaturated constituents (alkene double bonds) in fatty material along with ethanoic acid, followed by the determination of unreacted potassium iodate by titrating against a standard solution of sodium thiosulfate in the presence of potassium iodide via the iodometric method. The iodine value of various edible oils determined by the new reagent potassium iodate was found to agree with the results of standard methods like the Hnaus method.
\end{abstract}

Keywords: potassium iodate; iodine number; iodimetry.

(C) 2021 by the authors. This article is an open-access article distributed under the terms and conditions of the Creative Commons Attribution (CC BY) license (https://creativecommons.org/licenses/by/4.0/).

\section{Introduction}

There is an exceptional significance in determining the total unsaturation of oils because of industrial importance. Iodine value or iodine number measures the number of double bonds in the unsaturated fatty acids in one gram of oil. Determination of iodine values has been widely reported in the literature by different methods. Determination of iodine value is routinely done via the method developed by the Wijis method [1] and by Hanus and Rosenmund-Kuhnhenn method. [2,3]. Iodine values have been determined by using chloramine-T as reagent [4,5], without using Wijs solution (ICI) [4], and determination of iodine values by instrumental methods of analysis are well documented like Proton-NMR [6,9], IR transmission [10.11, ], near-infrared (NIR) reflectance and transmittance determination of iodine value and cis/trans distribution [12, 13], NIR Raman measurements [14], UV-Vis measurements [15, 16], the colorimetric method [17] potentiometric methods [18] and by triglyceride composition [19]. In continuation of our work on exploring the synthetic and analytical applications of potassium iodate [20], we were prompted to use it, which function as an excellent reagent to determine the extent of double bonds in an oil or fat moiety by a simple titrimetric method. The method outlined here makes use of the fact that the presence of ethanoic acid, potassium iodate adds on to the alkene to form alkenones with the liberation of iodous acid, thereby involving one mole of potassium iodate per alkene bond, makes an 
effectual method for the estimation of iodine value of edible oils of known mass. The results obtained were compared with the standard procedure of the American Oil Chemist's Society Cd-1-25 method, essentially the Hanus method. Vegetable oils from ten different sources were analyzed by the proposed method and were compared with the Hanus method, and statistical comparison showed that both the methods offered equivalent results.

\section{Materials and Methods}

All the common reagents employed in this method were procured from commercial supplies and were used without any further purification. Potassium iodate, ethanoic acid, potassium iodide, sodium thiosulfate used were Analytical grade reagents. Distilled water was employed. Sunflower, Groundnut, olive, castor, gingelly, palm, mustard, and coconut oils were used. Potassium iodate $\left(0.1 \mathrm{~mol} \mathrm{l}^{-1}\right)$ in a glacial ethanoic acid medium was used.

\subsection{Experimental.}

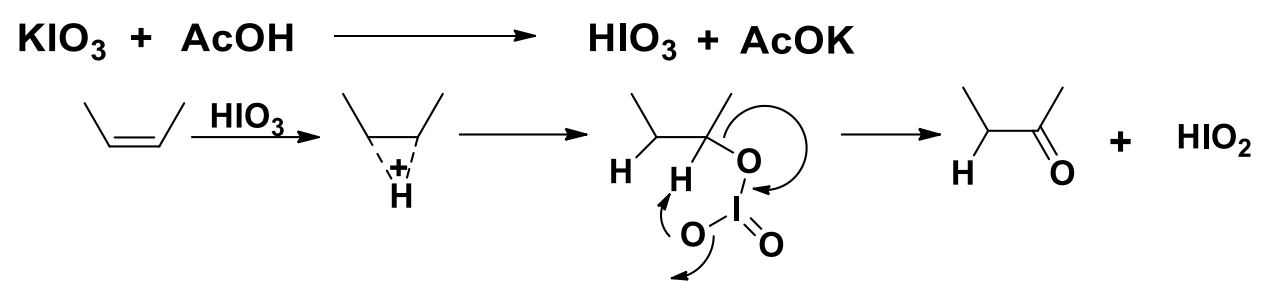

Scheme 1. Proposed mechanism for the reaction between the alkene and potassium iodate.

In this present work, a known excess of a standardized solution of potassium iodate is added to a known quantity of oil in an ethanoic acid medium. The whole mixture was kept for 1-2 $\mathrm{hr}$ after the reaction gets completed; the reagent left unreacted was determined by iodimetry. Blank titration is carried out simultaneously to ascertain the amount of potassium iodate reacted in the reaction. The proposed mechanism of the reaction of potassium iodate is depicted in Scheme 1. As the overall reaction required one mole of potassium iodate per $\mathrm{C}=\mathrm{C}$ unit, which is equivalent to one mole of iodine, the iodine number is determined using the following equations. $1 \mathrm{ml}$ of $0.1 \mathrm{~mol} \mathrm{l}^{-1}$ sodium thiosulfate solution $=12.69 \mathrm{mg}$ of iodine.

$$
\text { Iodine number }=\frac{(\mathrm{V} 1-\mathrm{V} 2) \times 12.69 \times 100 \times M}{m \times 0.1}
$$

Where, $\mathrm{V} 1$ = volume of $\mathrm{Na}_{2} \mathrm{~S}_{2} \mathrm{O}_{3}$ solution (hypo solution) required for the blank, $\mathrm{V} 2$ = volume of $\mathrm{Na}_{2} \mathrm{~S}_{2} \mathrm{O}_{3}$ solution (hypo solution) for the actual experiment, $M=$ molarity of $\mathrm{Na}_{2} \mathrm{~S}_{2} \mathrm{O}_{3}$ solution and $m=$ weight of oil (mg).

\subsection{Procedure.}

An accurately measured (50-100 mg) oil sample was taken in a clean, dry iodine flask. A standard solution of potassium iodate $\left(10 \mathrm{~mL}\right.$ of $\left.0.1 \mathrm{~mol} \mathrm{l}^{-1}\right)$ in glacial ethanoic acid was added and kept at room temperature for 1-2 hr. A blank titration was performed by transferring an equal volume of potassium iodate solution into an iodine flask and allowed to stand for $2 \mathrm{~h}$ under identical conditions. After this, $10 \%$ potassium iodide $(10 \mathrm{ml}), 1 \mathrm{~mol} \mathrm{l}^{-1}$ sulfuric acid (10 $\mathrm{ml})$, and water $(50 \mathrm{ml})$ and were added to each of the flasks, and the released iodine was titrated against standard thiosulfate solution $\left(0.1 \mathrm{~mol} \mathrm{l}^{-1}\right)$ using starch as an indicator. The iodine 
number was calculated from the difference in the tire values of sodium thiosulfate solution obtained from blank and back titration.

\section{Results and Discussion}

The iodine values of different edible oils achieved by the put-forwarded method, Hanus method, and literature value are compared and are tabulated in Table 1. The iodine values of each oil are derived in six trials, where they exhibited good reproducibility. Further, the standard deviation for all the samples was found to be less than $1 \%$ of the iodine value. Henceforth, the proposed method results are concordant with the results obtained by conventional methods and fall well within the range of literature values. The iodine value was determined by taking different weights and is given in Table 1 .

Table 1. Iodine number of oils.

\begin{tabular}{|c|c|c|c|c|c|c|c|c|c|c|}
\hline & \multicolumn{6}{|c|}{ Experimental Values* } & \multirow[t]{2}{*}{$\begin{array}{c}\text { Average } \\
\text { Value }\end{array}$} & \multirow[t]{2}{*}{$\begin{array}{c}\text { Std. Deviation } \\
(\%)\end{array}$} & \multirow[t]{2}{*}{$\begin{array}{l}\text { Lit. } \\
\text { Value }\end{array}$} & \multirow[t]{2}{*}{$\begin{array}{l}\text { Hanus } \\
\text { Method }\end{array}$} \\
\hline Oil & $\mathbf{1}$ & 2 & 3 & 4 & 5 & 6 & & & & \\
\hline Groundnut & $\begin{array}{l}94.2 \\
(45)\end{array}$ & $\begin{array}{l}93.7 \\
(85)\end{array}$ & $\begin{array}{l}92.10 \\
(100)\end{array}$ & $\begin{array}{l}92.44 \\
(150)\end{array}$ & $\begin{array}{c}93.2 \\
(140)\end{array}$ & - & 93.13 & 0.78 & $84-100$ & 94.10 \\
\hline Castor & $\begin{array}{l}88.4 \\
(50)\end{array}$ & $\begin{array}{l}88.2 \\
(90)\end{array}$ & $\begin{array}{c}87.6 \\
(100)\end{array}$ & $\begin{array}{l}87.89 \\
(135)\end{array}$ & $\begin{array}{c}87.9 \\
(190)\end{array}$ & - & 88.0 & 0.28 & $81-91$ & 88.0 \\
\hline Olive & $\begin{array}{l}81.2 \\
(50)\end{array}$ & $\begin{array}{l}80.8 \\
(55)\end{array}$ & $\begin{array}{l}80.1 \\
(75)\end{array}$ & $\begin{array}{c}81.1 \\
(100)\end{array}$ & $\begin{array}{c}80.2 \\
(120)\end{array}$ & - & 81.0 & 0.55 & $79-88$ & 80.0 \\
\hline Gingelly & $\begin{array}{l}96.2 \\
(75)\end{array}$ & $\begin{array}{c}95 \\
(130)\end{array}$ & $\begin{array}{c}95.1 \\
(120)\end{array}$ & $\begin{array}{c}95.2 \\
(120)\end{array}$ & $\begin{array}{l}94.9 \\
(100)\end{array}$ & - & 95.1 & 0.50 & $103-117$ & 95.02 \\
\hline Palm & $\begin{array}{c}53.16 \\
(69)\end{array}$ & $\begin{array}{c}53.23 \\
(89)\end{array}$ & $\begin{array}{l}52.8 \\
(116)\end{array}$ & $\begin{array}{l}53.73 \\
(122)\end{array}$ & $\begin{array}{l}54.3 \\
(142)\end{array}$ & $\begin{array}{l}52.5 \\
(104)\end{array}$ & 53.29 & 0.59 & $44-58$ & 53.50 \\
\hline Coconut & $\begin{array}{l}8.85 \\
(94) \\
\end{array}$ & $\begin{array}{c}9.14 \\
(116)\end{array}$ & $\begin{array}{c}8.56 \\
(152)\end{array}$ & $\begin{array}{c}8.70 \\
(172)\end{array}$ & $\begin{array}{l}8.55 \\
(124)\end{array}$ & $\begin{array}{c}9.15 \\
(130)\end{array}$ & 8.83 & 0.24 & $7.5-10.5$ & 8.85 \\
\hline Mustard & $\begin{array}{c}103.6 \\
(66)\end{array}$ & $\begin{array}{c}102.8 \\
(91)\end{array}$ & $\begin{array}{c}103.7 \\
(47)\end{array}$ & $\begin{array}{c}102.4 \\
(95)\end{array}$ & $\begin{array}{l}103.2 \\
(120)\end{array}$ & $\begin{array}{l}103.8 \\
(130)\end{array}$ & 103.26 & 0.49 & 103 & 103.12 \\
\hline Sunflower & $\begin{array}{c}124.4 \\
(50)\end{array}$ & $\begin{array}{c}124.2 \\
(90)\end{array}$ & $\begin{array}{l}126.1 \\
(107)\end{array}$ & $\begin{array}{l}124.9 \\
(130)\end{array}$ & $\begin{array}{l}124.1 \\
(190)\end{array}$ & - & 124.74 & 0.92 & $124-136$ & 124.70 \\
\hline Safflower & 145.4 & 145.5 & 146.2 & 145.0 & 146.2 & - & 145.66 & 0.42 & 145 & 145.20 \\
\hline
\end{tabular}

*Figures in parentheses represent mass $(\mathrm{mg})$ of the oil taken for estimation.

By the stastical treatment performed on the results obtained indicates that the proposed method gives equivalent precision values compared to other methods.

A possible analysis of the proposed method with respect to the volatilization of iodine might be expected to occur during the procedure. Nevertheless, as can be seen from the experimental results, no significant difference among the methods could imply the ruling out of this problem. This means that cooled water is added during titration to avoid a significant loss of iodine. However, an ice bath can also be used to guarantee a low enough temperature for the iodine solution. The method reported in this paper has the following advantages over the existing methods. i) Preparation of the reagent potassium iodate takes few minutes in comparison with the lengthy time needed to prepare Wijs reagent; ii) Proposed procedure is cost-effective; iii) Prepared reagent was found to be stable for more than a week and gave satisfactory results to determine the iodine values of the edible oils; iv) The employed method reduces the amount of solvent.

However, it should be noted that the use of glacial acetic acid can cause eye damage, skin burns, and irritation to the mucous membrane, so care should be taken while handling this chemical. 
Considering the results obtained with the proposed method in terms of safety, reliability, environmental concern, precision, and reliability, the new reagent potassium iodate can be employed for the iodine value determination of edible oils.

\section{Conclusions}

From the findings of this research work, we concluded that utilizing potassium iodate as a new reagent combined with iodometric titration affords the determination of iodine value of edible oils with precision, cost-effective, simpler, and greener (with less toxic chemicals) compared to all other methods for the iodine value estimation. This method of ascertaining the iodine value of edible oils can also be employed for the quantitative determination of nonconjugated and conjugated tetraene, triene, diene of different samples.

\section{Funding}

This research received no external funding.

\section{Acknowledgments}

The authors are grateful to the Management, Vidyavardhaka College of Engineering, Mysuru, and the University of Mysore for providing the necessary facility to carry out the research work.

\section{Conflicts of Interest}

The authors declare no conflict of interest.

\section{References}

1. McCutcheon, J.W. Wijs Iodine Method. Industrial \& Engineering Chemistry Analytical Edition 1940, 12, 465-465, https://doi.org/10.1021/ac50148a012.

2. Norris, F.; Buswell, R. Rapid Iodine Number Determinations. Industrial \& Engineering Chemistry Analytical Edition 1943, 15, 258-259, http://doi.org/10.1021/i560116a008.

3. Harvey Benham, G.; Klee, L. An improved method for the determination of iodine numbers. Journal of the American Oil Chemists' Society 1950, 27, 127-129, https://doi.org/10.1007/BF02634381.

4. Rai, K.M.L.; Anjanamurthy, C.; Ambekar, S.Y. Determination of iodine number of oils using Chloramine-T as reagent. Analyst 1995, 120, 2769-2770, http://doi.org/10.1039/AN9952002769.

5. Nagendrappa, G.; Urs, S.S.R.; Rajalakshmi, S. Chloramine T with iodine: A new reagent to determine the iodine value fo edible oils. Journal of the American Oil Chemists' Society 1998, 75, 1219-1221, https://doi.org/10.1007/s11746-998-0138-0.

6. Shimamoto, G.G.; Aricetti, J.A.; Tubino, M. A Simple, Fast, and Green Titrimetric Method for the Determination of the Iodine Value of Vegetable Oils Without Wijs Solution (ICl). Food Analytical Methods 2016, 9, 2479-2483, https://doi.org/10.1007/s12161-016-0401-1.

7. Di Pietro, M.E.; Mannu, A.; Mele, A. NMR Determination of Free Fatty Acids in Vegetable Oils. Processes 2020, 8, https://doi.org/10.3390/pr8040410.

8. Kumar, R.; Bansal, V.; Patel, M.B.; Sarpal, A.S. 1H Nuclear Magnetic Resonance (NMR) Determination of the Iodine Value in Biodiesel Produced from Algal and Vegetable Oils. Energy \& Fuels 2012, 26, 7005-7008, https://doi.org/10.1021/ef300991n.

9. Tang, F.; Green, H.S.; Wang, S.C.; Hatzakis, E. Analysis and Authentication of Avocado Oil Using High Resolution NMR Spectroscopy. Molecules 2021, 26, https://doi.org/10.3390/molecules26020310.

10. Sedman, J.; van de Voort, F.R.; Ismail, A.A.; Maes, P. Industrial validation of fourier transform infrared trans and lodine value analyses of fats and oils. Journal of the American Oil Chemists' Society 1998, 75, 33-39, https://doi.org/10.1007/s11746-998-0006-y.

11. Hendl, O.; Howell, J.A.; Lowery, J.; Jones, W. A rapid and simple method for the determination of iodine values using derivative Fourier transform infrared measurements. Analytica Chimica Acta 2001, 427, 75-81, https://doi.org/10.1016/S0003-2670(00)01193-4.

12. Varghese, G.; Saeed, K.; Rutt, K.J. Determination of the oxidative stability of biodiesel fuels by near-infrared spectroscopy. Fuel 2021, 290, https://doi.org/10.1016/j.fuel.2020.120015. 
13. Li, H.; van de Voort, F.R.; Ismail, A.A.; Sedman, J.; Cox, R. Trans determination of edible oils by fourier transform near-infrared spectroscopy. Journal of the American Oil Chemists' Society 2000, 77, 1061-1067, https://doi.org/10.1007/s11746-000-0167-5.

14. Dymińska, L.; Calik, M.; Albegar, A.M.M.; Zając, A.; Kostyń, K.; Lorenc, J.; Hanuza, J. Quantitative determination of the iodine values of unsaturated plant oils using infrared and Raman spectroscopy methods. International Journal of Food Properties 2017, 20, 2015, https://doi.org/10.1080/10942912.2016.1230744.

15. Brooks, A.B.; Swain, M.L. Ultraviolet Absorption Method for the Determination of Polyunsaturated Constituents in Fatty Materials. J. Opt. Soc. Am. 1945, 35, 532-544.

16. Kapoulas, V.M.; Andrikopoulos, N.K. Detection of virgin olive oil adulteration with refined oils by secondderivative spectrophotometry. Food Chemistry 1987, 23, 183-192, https://doi.org/10.1016/03088146(87)90138-5.

17. a) Soares, S.; Rocha, F. Fast Spectrophotometric Determination of Iodine Value in Biodiesel and Vegetable Oils. Journal of the Brazilian Chemical Society 2018, 29, https://doi.org/10.21577/0103-5053.20180044. b) Peamaroon, N.; Jakmunee, J.; Moonrungsee, N. A Simple Colorimetric Procedure for the Determination of Iodine Value of Vegetable Oils Using a Smartphone Camera. Journal of Analysis and Testing 2021, https://doi.org/10.1007/s41664-021-00168-x.

18. Tubino, M.; Aricetti, J.A. A green potentiometric method for the determination of the iodine number of biodiesel. Fuel 2013, 103, 1158-1163, https://doi.org/10.1016/j.fuel.2012.10.011.

19. Haryati, T.; Che Man, Y.B.; Ghazali, H.M.; Asbi, B.A.; Buana, L. Determination of iodine value of palm oil based on triglyceride composition. Journal of the American Oil Chemists' Society 1998, 75, 789-792, https://doi.org/10.1007/s11746-998-0227-0.

20. Km, L.R.; PrakruthiAiyappa, K.; Bl, H.; Ks, C. Iodometric determination of glucose and ribose using potassium iodate as novel reagent in acetic acid medium. J Anal Pharm Res 2019, 8, 185-186, https://doi.org/10.15406/japlr.2019.08.00336. 